\title{
Conhecimentos e práticas de trabalhadoras de creches municipais relativos ao cuidado da criança com infecção respiratória aguda
}

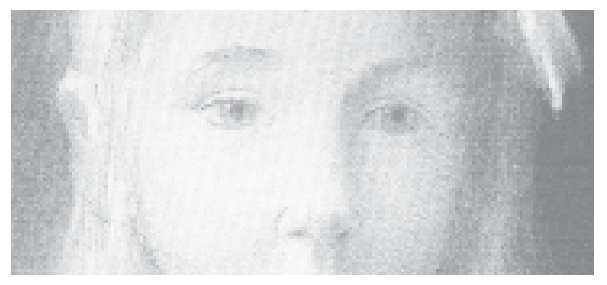

\author{
Juliana Martins ${ }^{1}$ \\ Maria de La Ó Ramalho Veríssimo²
}

MARTINS, J.; VERÍSSIMO, M. L. Ó. R. Experience and practices of municipal day care workers regarding taking care of children with acute respiratory infection. Interface - Comunic., Saúde, Educ., v.10, n.20, p.487-504, $\mathrm{jul} / \mathrm{dez} 2006$.

This study identified experiences and practices used by day care center workers in regard to prevention, early diagnosis and care of children with acute respiratory infections, given the extent of the problem in these locations. The data was collected during semi-structured interviews carried out with 14 children social workers and two nurse assistants from two municipal day care centers. The data was then organized in categories through thematic analysis of content and themes were quantified. Bronchitis was the most remembered illness, and fever, coughing and fatigue were the symptoms most mentioned; the seriousness were seldom mentioned; reference was made to negligence by mothers in causing ailments; many workers stated that they did not know how curb the occurrence of these illnesses. Some workers mentioned appropriate measures on how to carry out child care, but the majority based their actions on common sense and are unaware of specific care. Improvement of workers knowledge may help systematize care, as upheld by the Health Schools model.

KEY WORDS: child health. child day-care centers. respiratory tract infections. professional practice. school health.

Este trabalho identificou conhecimentos e práticas de trabalhadoras de creches relativos à prevenção, detecção precoce e manejo das infecções respiratórias agudas na infância, dada sua magnitude nesses locais. Após análise temática de conteúdo, os dados obtidos em entrevistas semi-estruturadas, com 14 auxiliares de desenvolvimento infantil e dois auxiliares de enfermagem de duas creches públicas, foram categorizados $e$ quantificados. Bronquite foi o agravo mais lembrado, assim como febre, tosse e cansaço foram os sinais de doença mais referidos; os sinais de gravidade foram pouco citados; houve referência de associação das doenças ao descuido materno; muitas trabalhadoras referem desconhecer intervenções para diminuir a ocorrência desses agravos. Parte das trabalhadoras relatou ações apropriadas para o cuidado infantil, a maioria fundamenta suas ações no senso comum e desconhece cuidados específicos. A melhoria de conhecimentos pode favorecer a sistematização do cuidado, como preconizado no modelo das Escolas Promotoras de Saúde.

PALAVRAS-CHAVE: saúde da criança. creches. infecções respiratórias. prática profissional. saúde escolar.

${ }^{1}$ Departamento de Pediatria, Hospital Universitário, Universidade de São Paulo. <ju310781@yahoo.com.br>

${ }^{2}$ Departamento de Enfermagem Materno-Infantil e Psiquiátrica, Escola de Enfermagem, Universidade de São Paulo. <mdlorver@usp.br>

${ }^{1}$ Rua Caiubí, 1276, apto. 64

Perdizes - São Paulo, SP

Brasil - 05.010-000 


\section{Introdução}

A mortalidade infantil no Brasil vem apresentando taxas menores a cada ano, mas ainda apresenta índices elevados em algumas regiões do país, bem como em grupos populacionais que têm condições de vida precárias. Assim, a estimativa brasileira de mortalidade infantil em 2002, de 25,06, não exprime a realidade encontrada em muitos municípios do país e periferias de grandes cidades (Datasus, 2005a).

No Brasil, as infecções respiratórias agudas (IRA) encontram-se entre as principais causas de morbidade e mortalidade infantil. Na cidade de São Paulo, aparecem como a primeira causa de óbitos infantis na faixa de um a quatro anos, compreendendo cerca de $25 \%$ destes, sendo a pneumonia a primeira causa isolada de mortalidade (Datasus, 2005b). Ainda, constituem a principal causa de consulta médica por doença na rede pública e de 20 a $40 \%$ das internações pediátricas (Brasil, 2002).

A freqüência à creche é importante fator de risco para a ocorrência de IRA, devido a maior exposição das crianças aos agentes infecciosos pelo confinamento e aglomeração (Victora, 1998).

Uma pesquisa acerca da mortalidade de crianças usuárias de creches no município de São Paulo constatou que $36,8 \%$ dos óbitos, no período de 1995 a 1999, foram por doenças respiratórias, sendo 29,6\% por pneumonia. Nos menores de um ano, as doenças respiratórias foram responsáveis por $49,3 \%$ dos óbitos e atingiram $51 \%$ nas crianças de um a dois anos, índices que foram diminuindo nas idades superiores (Vico, 2001). Verificam-se, assim, maiores taxas de óbito por tais afecções na população de creches do que na população em geral, que ficou em torno de $25 \%$ nesse período (Datasus, 2006).

Observando os resultados do estudo de Vico (2001), parece-nos que a mortalidade total entre as crianças que freqüentam creches seria inferior à mortalidade da população infantil em geral, mas a pesquisa não analisou os dados dessa forma. Seria importante a realização de estudos que pudessem esclarecer essa dimensão.

Atualmente, as creches ${ }^{3}$ estão alocadas no setor da educação, sendo preconizado, pela Lei de Diretrizes e Bases da Educação Nacional (LDB), que a formação mínima de docentes para atuar na Educação Infantil seja de nível médio, modalidade magistério ou normal (Brasil, 1996). Com isto, pretende-se aprimorar o atendimento oferecido às crianças nessas instituições, dada a importância dos primeiros anos de vida no processo de desenvolvimento humano.

Entretanto, ainda existem grandes variações na formação e capacitação profissional entre as trabalhadoras responsáveis pelo atendimento direto às crianças nesses locais. Isto se reflete nas diferentes denominações atualmente atribuídas a elas, tais como: auxiliar de desenvolvimento infantil (àquelas que não têm formação específica) ou professora de desenvolvimento infantil (as que têm formação específica e foram aprovadas em concurso), adotadas na Secretaria Municipal de Educação de São Paulo.

Em que pesem essas diferenças, essas trabalhadoras, em geral, vêem o cuidado à criança como algo que não demanda habilidades ou

\footnotetext{
${ }^{3}$ Atualmente, a Educação Infantil engloba creches, que atendem crianças de zero a três anos, e préescolas, que atendem crianças de quatro a seis anos. Utilizaremos o termo creche neste artigo, embora as instituições estudadas contem com crianças de zero a cinco anos, considerando que este é o descritor mais conhecido na área.
} 
conhecimentos específicos, de menor valor e subsidiário em relação à educação (Veríssimo \& Fonseca, 2003). Tal compreensão relaciona-se à insuficiência da sua formação escolar para "o atendimento aos cuidados essenciais associados à sobrevivência e ao desenvolvimento da identidade" da criança (Brasil, 1998). O foco dessa formação centra-se na educação, mais especificamente, em disciplinas e conteúdos escolares (Veríssimo, 2001). Como afirma Barreto (1994), é um desafio para os mecanismos de formação contemplar a dupla função de educar e cuidar na educação infantil.

Além disso, as instituições de educação infantil devem "garantir qualidade não só no aspecto individual da educação e cuidados, mas também naqueles de ordem coletiva e epidemiológica que minimizem riscos à saúde e promovam o pleno crescimento e desenvolvimento das crianças" (Vico, 2001, p.17), o que justifica o aprimoramento do cuidado relacionado ao controle das IRA nesses locais.

A Organização Panamericana de Saúde (OPAS) preconiza as atividades educativas em saúde como uma das frentes para o controle das IRA (Benguigui, 1998). Isto se justifica uma vez que medidas apropriadas de prevenção, detecção precoce de sinais de doença, principalmente sinais de gravidade, $e$ manejo adequado dos principais agravos que acometem crianças pequenas, dependem dos conhecimentos que sustentam as práticas de cuidado no domicílio e em outros locais onde as crianças permanecem no seu dia-a-dia.

Entre as medidas de promoção da saúde e prevenção de agravos respiratórios, destacam-se: imunização, aleitamento materno, alimentação nutricionalmente adequada, higiene ambiental e pessoal para prevenção de disseminação de infecções - em especial, lavagem das mãos, higiene nasal, manutenção de ventilação no ambiente e desinfecção de objetos manuseados pelas crianças (Benguigui, 1998; Veríssimo \& Sigaud, 2001).

Em relação ao manejo adequado, inclui-se tanto a atenção padronizada pelos trabalhadores de saúde quanto o reconhecimento precoce de sinais de gravidade, ou seja, respiração rápida e dificuldade para respirar, demonstrada por retrações na caixa torácica. A presença desses sinais demanda atenção de saúde imediata e, portanto, é recomendado que todos os cuidadores infantis saibam identificá-los. Conforme Benguigui (1998), é fundamental que os responsáveis pelas crianças saibam quando devem buscar atenção fora de casa, bem como compreendam a necessidade de implementar corretamente as terapêuticas prescritas, uma vez que o tratamento antimicrobiano é essencial para a redução da mortalidade por pneumonia.

Estas medidas de controle das IRA atualmente estão sistematizadas pela estratégia de Atenção Integrada às Doenças Prevalentes na Infância (AIDPI) (Veríssimo \& Sigaud, 2001).

Além disso, os primeiros anos de vida da criança são um período de formação de hábitos, que poderão durar por toda a vida, tais como o cuidado de si, da própria saúde. Sendo assim, a instituição educativa se constitui excelente lugar para aplicação de programas de promoção da saúde, que podem contribuir para a melhoria das práticas de cuidado diretamente oferecido às crianças, bem como estimular a adoção de hábitos saudáveis desde a infância.

Para atender a esta perspectiva ampla do cuidado de saúde, a instituição educativa pode apoiar-se num referencial que supere a abordagem tradicional centrada em práticas curativas e higienistas. O referencial das Escolas 
Promotoras da Saúde responde a esta perspectiva, pois é uma estratégia de promoção da saúde no âmbito escolar, fundamentada nos princípios de educação para a saúde com enfoque integral e multidisciplinar; criação e manutenção de ambientes saudáveis e provisão de serviços de saúde para escolares (IppolitoShepher, 2003). Visa contribuir para a alfabetização em saúde que é "a capacidade para obter, interpretar e compreender informação básica sobre saúde e serviços, e a competência para usar essas informações e serviços para a melhoria das condições de saúde" (Ippolíto-Shepher, 2003, p.41).

Como uma das etapas do desenvolvimento de um projeto de pesquisa $e$ extensão universitária, fundamentado nos pressupostos das escolas promotoras de saúde, realizou-se o presente estudo, que teve como objetivo identificar conhecimentos e práticas de auxiliares de desenvolvimento infantil e auxiliares de enfermagem de creches municipais relativos à prevenção, detecção precoce e ao manejo das infecções respiratórias agudas infantis.

\section{Metodologia}

O estudo foi realizado em 2002, em duas creches de administração direta do município de São Paulo, na região do Butantã, indicadas pela coordenação do NAE-12 (Núcleo de Ação Educativa), órgão responsável pelas creches municipais dessa região, considerando a percepção da coordenadora de que essas instituições seriam receptivas à pesquisa.

Ambas as creches atendiam cerca de 130 crianças e, na época, todas as trabalhadoras que atuavam diretamente com as crianças eram denominadas Auxiliares de Desenvolvimento Infantil (ADIs), independente de sua formação. Uma contava com uma auxiliar de enfermagem e a outra com duas, porém uma delas não se encontrava em atividade no período da coleta de dados. Cada creche tem uma diretora e é supervisionada por uma encarregada do NAE-12. A orientação pedagógica é definida por uma pedagoga do NAE e a programação das atividades é feita em conjunto pela diretora e ADIs.

A amostra foi constituída por 14 ADIs (cerca de $30 \%$ do total em atividade), indicadas pelas diretoras das creches $e$ as duas auxiliares de enfermagem. Definiu-se esta população, pois as ADIs ficam permanentemente com as crianças, realizando todas as atividades educativas $e$ de cuidado, $e$ as auxiliares de enfermagem são as responsáveis pelas decisões relativas ao cuidado de saúde das crianças no serviço. O número de ADIs foi delimitado pela saturação das informações.

A coleta de dados deu-se mediante entrevistas semi-estruturadas, realizadas pela pesquisadora, após treinamento. Partia-se de perguntas elaboradas anteriormente, e, quando necessário, eram citados alguns exemplos ou solicitados maiores esclarecimentos, para dar continuidade à entrevista. $\mathrm{O}$ formulário de entrevista foi pré-testado e continha uma parte de caracterização dos sujeitos e uma parte de questões abertas sobre conhecimentos e práticas relacionados às IRA.

O projeto foi apreciado por Comitê de Ética e pela coordenação das creches do município de São Paulo. As trabalhadoras, após esclarecidas de acordo com as normas para pesquisa com seres humanos, expressaram seu consentimento assinando o termo de consentimento livre e esclarecido. 
As entrevistas foram gravadas, transcritas integralmente e submetidas à análise temática de conteúdo, que "consiste em descobrir os núcleos de sentido que compõem uma comunicação cuja presença ou freqüência signifiquem alguma coisa para o objetivo analítico visado" (Minayo, 1993, p.209). As fases seguidas para a análise temática foram leitura repetida das transcrições, buscando apreender as idéias de forma compreensiva; identificação dos temas presentes nos discursos $e$ agrupamento dos temas segundo sua relação com as categorias de análise predefinidas. O referencial para discussão dos resultados foi o modelo das Escolas Promotoras da Saúde e a Estratégia de Atenção Integrada às Doenças Prevalentes da Infância.

Os dados das ADIs e auxiliares de enfermagem foram analisados inicialmente em separado. Após a análise, optamos por apresentar em conjunto os resultados que não evidenciavam diferenças qualitativas entre os dois tipos de trabalhadoras e separadamente aqueles qualitativamente diferentes. Assim, utilizamos o termo trabalhadoras para nos referirmos a ambas as categorias e, quando necessário destacar uma ou outra categoria, utilizamos especificamente os termos ADIs ou auxiliares de enfermagem. Os resultados que se mostraram diferentes, segundo a escolaridade das trabalhadoras, estão discriminados. Foram utilizadas duas categorias de escolaridade: nível médio (62,5\%), aquelas com ensino médio completo e superior incompleto, e nível fundamental (37,5\%), aquelas com ensino fundamental incompleto e ensino médio incompleto.

\section{Resultados}

\section{Caracterização das trabalhadoras}

As idades das trabalhadoras situavam-se na faixa de 41 a 63 anos, e todas eram do sexo feminino. Nove (56\%) entrevistadas tinham ensino médio completo, e duas (12,5\%), o magistério; três (19\%) estavam cursando o magistério nível médio; uma (6\%) tinha ensino médio incompleto; duas (12,5\%) ensino fundamental incompleto ( $4^{\mathrm{a}}$ e $6^{\mathrm{a}}$ série), e uma (6\%) trabalhadora possuía ensino superior incompleto. As duas auxiliares de enfermagem cursaram o ensino médio completo. O menor tempo de trabalho com educação infantil foi de três anos, e 69\% (11) estavam há mais de dez anos nas creches do estudo.

Quanto à capacitação específica em educação infantil, cinco (31\%) se referiram ao treinamento de uma semana à época da admissão na creche (incluindo quem entrou há um ano e meio, assim como quem entrou há 15 anos), e cinco (31\%) citaram cursos esporádicos realizados pela prefeitura. Os conteúdos do treinamento e dos cursos não foram relatados. Três (19\%) entrevistadas disseram não ter nenhum tipo de capacitação específica; duas $(12,5 \%)$ citaram palestras; uma (6\%) citou o magistério, e uma $(6 \%)$ um curso de baby-sitter.

A maioria das ADIs exerceu ou exercia, na época, outras atividades de trabalho não relacionadas à educação infantil. Ao serem questionadas sobre o hábito de leitura, a maioria revelou ler esporadicamente jornais, revistas ou livros. 


\title{
Conhecimentos de trabalhadoras de creches sobre problemas respiratórios na infância
}

Esta categoria originou-se dos temas: "problemas respiratórios conhecidos"; "problemas respiratórios mais comuns na creche"; "sinais dos problemas respiratórios"; "sinais de gravidade dos problemas respiratórios", e "causas dos problemas respiratórios".

Apenas uma (6\%) trabalhadora disse não se lembrar de qualquer problema respiratório, dez $(62,5 \%)$ citaram nomes científicos e sinais clínicos, e cinco (31\%) apenas sinais clínicos. Duas (12,5\%) ADIs somente responderam após a entrevistadora ter citado alguns exemplos, visando a continuidade da entrevista. O agravo mais citado foi bronquite (mencionada por $50 \%$ ), seguido de falta de ar/canseira (37,5\%), pneumonia (19\%), asma (12,5\%), rinite $(12,5 \%)$, resfriado $(12,5 \%)$, além de tuberculose, laringite, tosse, chiado, coriza, olhos fundos, sinusite, enfisema pulmonar, "IVAS", alergia a pó, crise alérgica, "ronquidão", dificuldade para respirar, engolir e sugar, citados apenas uma vez cada. Rinite e resfriado foram citados apenas por trabalhadoras com ensino fundamental.

Apesar de algumas participantes demonstrarem bastante segurança ao mencionar os problemas respiratórios conhecidos, outras demonstraram receio e dúvidas.

\author{
pelo nome, assim? Por nome eu não sei dizer. \\ Olha, eu não sei se seria, eu acho que é...?. \\ Ué bronquite, né? Bronquite, pneumonia, tuberculose tá fora, não tá?
}

Ao perguntarmos sobre os problemas respiratórios mais comuns na creche, lembrávamos dos problemas citados e ainda de outros que não haviam sido respondidos na primeira pergunta, mas que se constituem em problemas epidemiologicamente destacados.

O problema respiratório referido como mais comum na creche foi o resfriado (citado por $69 \%$ ), seguido de pneumonia (50\%), bronquite (50\%), gripe (44\%), infecção de garganta (37,5\%), infecção de ouvido (19\%), sendo citados, apenas uma vez, rinite alérgica, falta de ar, fadiga, crise alérgica, peito cheio e febre. A escolaridade não interferiu nas respostas.

Dentre os sinais de problemas respiratórios, em primeiro lugar, apareceu mudança de comportamento, tal como "criança quieta", "chorosa", "amuada", "fica molinha", "muda o comportamento" ( $81 \%$ das respostas); seguido de febre (50\%), perda de apetite (37,5\%), coriza (37,5\%), tosse (31\%), falta de ar/cansaço (19\%). Foram mencionados, ainda: "a criança se queixa" (12,5\%), espirro (12,5\%), olhos lacrimejando (12,5\%), "a criança pede muita água" (6\%). Perda de apetite, coriza e tosse foram citados em maior número pelas trabalhadoras com ensino fundamental.

Ah, pelo olhar, o jeito mesmo (...).

É a febre, aqui na creche é a febre.

(...) tem muita coriza, o nariz escorre, espirra bastante, tosse (...) 
O sinal identificado pela maioria como de gravidade foi a febre, e, pela minoria, outros como tosse, mudança de comportamento, coriza $e$ alterações da respiração (Gráfico 1); sendo citados, apenas uma vez: vômito, queixa da criança, resfriado constante, peito chiando, manchas no corpo.

Eu acho que é febre, febre alta.

A respiração, o olhar da criança (...).

No gráfico 2, aparecem as causas dos problemas respiratórios segundo as trabalhadoras. Clima inclui mudança de temperatura, friagem, poluição $e$ vento. Falta de cuidado das mães abarca falta de higiene, andar descalço, sair sem agasalho, tomar gelado. Causas ligadas ao biológico são: falta de vitamina, alergias, herança genética, má alimentação, desenvolvimento de cada criança. Em relação ao ambiente, aparecem: a umidade, cheiro de tinta $e$ de cera, falta de ventilação, poeira, pó. A transmissão foi relacionada ao contato com microorganismos e/ou ao início da freqüência da criança na creche, pela aglomeração de crianças.

Muita coisa vem do ar, poluição, é do tempo, é difícil...

(...) agora o que causa isto, eu acho que deve ser mesmo gripes $e$ resfriados malcurados.

(...) às vezes você fala, fala, e a mãe não cuida (...)

Ah, se é uma criança que sai descalço, a gripe pega primeiro pelo pé (...) crianças que sai descalço, um frio às vezes sai sem um agasalho adequado, entendeu, tomar coisa muito gelada...

Gráfico 1. Sinais de gravidade referidos pelas trabalhadoras, segundo escolaridade.

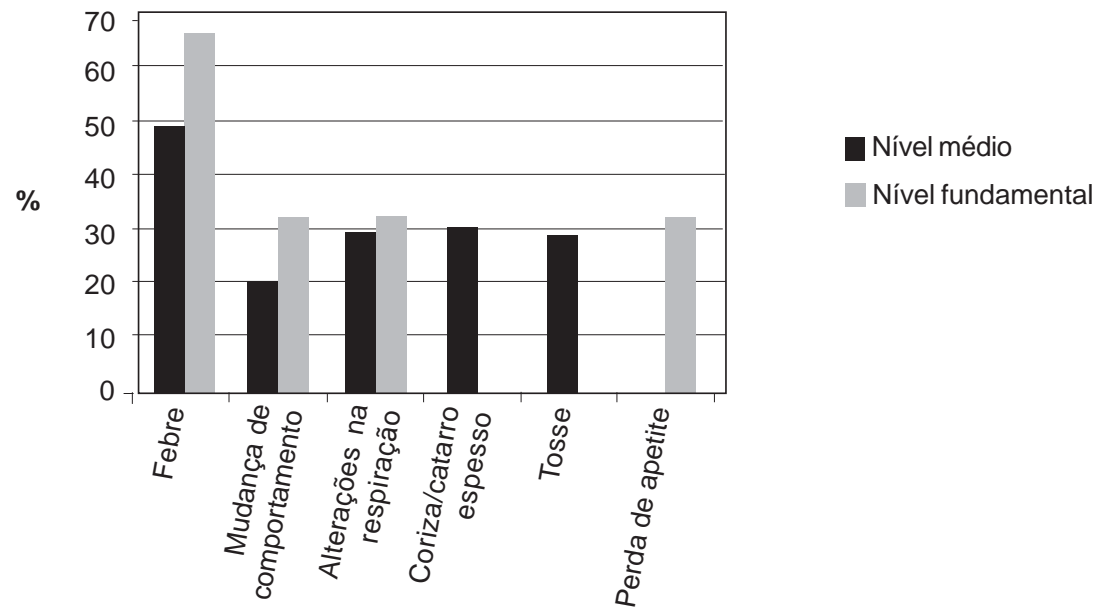


Gráfico 2. Causas dos problemas respiratórios citados pelas trabalhadoras, segundo escolaridade

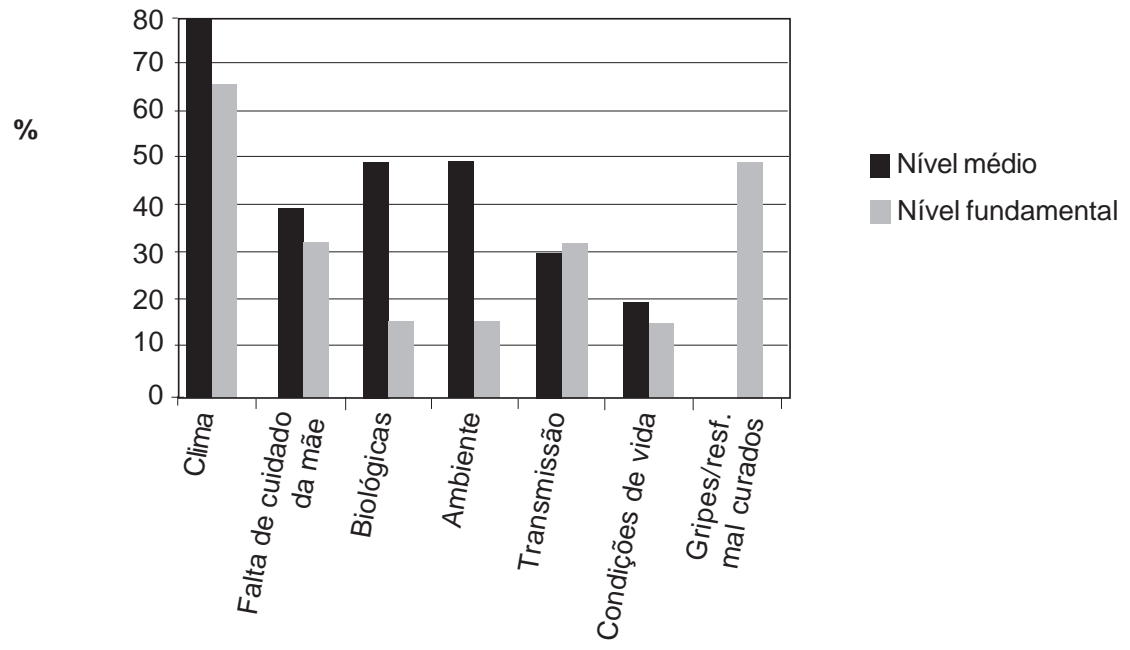

Quanto ao que as trabalhadoras consideravam importante saber para cuidar da criança com problema respiratório, a maioria das respostas $(62,5 \%)$ foi genérica, como: "saber cuidar direito", "saber o que fazer". Os exemplos de cuidado foram: saber como agir com a criança, o que fazer para ajudar, socorrer a criança, alimentar direito, agasalhar, saber tomar providências, e saber diferenciar os problemas respiratórios.

(...) eu acho que é necessário, sim, a gente estar sempre sabendo e aprendendo mais como tratar deles.

Importante a gente entender um pouquinho para poder socorrer a criança, poder fazer alguma coisa com ele até a mãe chegar.

Algumas trabalhadoras (44\%) relacionaram o cuidado ao conhecimento específico sobre o tema, destacando que precisariam de um melhor conhecimento para saber cuidar melhor. Houve referência à importância de "conhecer a situação da criança" (19\%) e "maior atenção por parte da ADI" (6\%). Uma das auxiliares de enfermagem disse que não há mais nada que as ADIs precisem saber, pois "as ADIs sabem de tudo", restando apenas realizar aquilo que sabem.

As fontes dos conhecimentos das trabalhadoras são bastante diversificadas, sendo citadas: a própria experiência de vida (56\%), a convivência com as crianças na creche (56\%), experiências com família, principalmente com os filhos (50\%), e leituras (37,5\%). Além destas, foram indicadas: orientações médicas (12,5\%), troca de informações com as colegas de trabalho $e$ treinamento recebido antes de entrar na creche (12,5\%), e diálogo com os pais 
(6\%). Uma auxiliar de enfermagem mencionou sua experiência de trabalho em hospital. A leitura foi citada em maior número por trabalhadoras com maior nível de escolaridade.

Olha, eu acho que isso daí, com o tempo, principalmente a gente quando é mãe, a gente vai aprendendo aos poucos $e$ as mães, as avós também falam muito sobre estas coisas.

Observando em separado as respostas das auxiliares de enfermagem, verifica-se que não há diferenças expressivas na maioria das questões: apenas uma delas nomeia agravos; ambas citam sinais clínicos para caracterizar os problemas respiratórios; associam, como suas causas, mudanças climáticas, falta de cuidado e de higiene, e têm, como principal fonte de conhecimento, a prática cotidiana. Porém, ambas citam sinais mais específicos (tosse e dificuldade para respirar) de IRA.

\section{A prática das trabalhadoras de creches relativa aos problemas respiratórios na infância}

Formou-se esta categoria pelos temas: "ações da ADI quando a criança tem sinal de problema respiratório"; "ações da trabalhadora de enfermagem na creche"; "medidas para controlar os problemas respiratórios"; "dificuldades para o cuidado da criança com problema respiratório".

As ações das ADIs, quando ocorre uma situação de problema respiratório, constituem, em sua maioria, ações de âmbito individual, destacando-se: encaminhar para a enfermagem, chamar a mãe, e atividades relacionadas diretamente aos sinais físicos, principalmente no que diz respeito à febre, $e$ promoção de conforto e bem-estar (Gráfico 3).

Se tiver febre alta, a gente pode até fazer compressas, ou dar um banho, não digo gelado, mas um pouco frio. Um banho, pra poder ajudar a baixar a febre.

Se ela estiver dormindo, procuro elevar mais a cabeça dela para que ela fique em uma posição com a cabeça mais elevada, observo mais.

A medicação aparece como uma prática realizada na creche, desde que haja autorização materna ou prescrição médica, e várias trabalhadoras ressaltaram o fato de não poderem dar medicação sem a autorização da mãe como um limite a suas ações:

A gente dá banho, medicar a gente não pode, é limpar o nariz, ficar observando, a gente dá água.

A limpeza nasal só acontece caso a secreção esteja saindo naturalmente, e não são realizadas freqüentemente medidas para fluidificar a secreção como, por exemplo, a instilação de soro nasal ou aumento da oferta de líquidos.

Chama a atenção que várias ADIs finalizam sua resposta dizendo não saber o que fazer com a criança que apresenta algum sinal de problema respiratório, ou que não há muito que fazer na creche nesses casos, mencionando falta de 
orientação e de recursos, ainda que algumas delas tenham citado ações apropriadas ao cuidado infantil.

Acho que é só, aqui não dá pra fazer muito, a gente não tem orientação.

Geralmente, é encaminhada pra estar levando ao hospital, alguma coisa do tipo, aqora, aqui dentro da unidade eu acho que a gente não tem recurso pra isto.

Entre as medidas de higiene para evitar a transmissão, foram citadas: deixar a sala bem arejada e ventilada (31\%); lavar bichinhos do berçário; separar colchonetes; deixar sempre o ambiente limpo; trocar diariamente os lençóis; orientar a criança a limpar o nariz com papel higiênico e depois lavar as mãos; ensinar a criança a colocar a mão na boca quando espirra; não secar a criança com a mesma tolha usada em outra; usar papel descartável para limpar o nariz; não misturar com os outros - citados uma vez cada. Apenas uma ADI mencionou várias destas medidas.

Ah, a gente procura deixar a sala bem ventilada, não secar a criança com a mesma toalha, trocar o lençol, porque geralmente elas dormem, aí tira o lençol que elas deixam aquela secreção no lençol, aí a gente troca (...).

Gráfico 3. Ações realizadas pelas ADIs quando ocorrem situações de problemas respiratórios na creche, segundo escolaridade.

$\%$

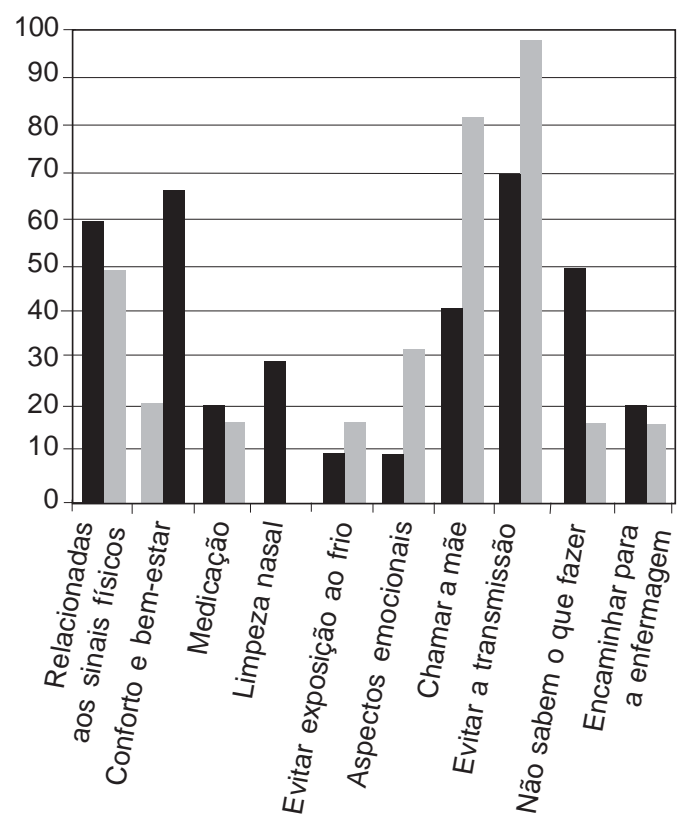

Nível médio

Nível fundamental 
(...) a gente orienta bem a criança de estar limpando o nariz com papel higiênico, lavando a mãozinha após limpar para não passar também para outras crianças (...)

(...) deixar sempre tudo muito arejado, pra que eles não tenham e a gente também não.

As auxiliares de enfermagem e três ADIs mencionaram ações que consideram serem exclusivas da trabalhadora de enfermagem, como: entrar em contato com a família, dar medicação e outros cuidados específicos (limpeza nasal, verificar temperatura), e providenciar encaminhamento ao serviço de saúde.

Aí encaminha pra enfermeira daqui, aí ela encaminha pra mãe levar ao médico, dá o encaminhamento.

Uma das auxiliares, ao ser questionada sobre suas ações com a criança com problema respiratório, disse que não podia fazer nada. Entretanto, logo em seguida citou várias medidas eficazes no controle dos problemas respiratórios, como tapotagem e preparação do soro caseiro para limpar as narinas.

A dificuldade mais citada pelas trabalhadoras, quando da ocorrência de agravo respiratório, foi a necessidade de maior atenção à criança (44\%), seguida de: dificuldade de encontrar a mãe (19\%), dificuldade na alimentação (19\%), a mãe levar a criança doente para a creche (12,5\%), dificuldades para evitar a transmissão (12,5\%), desconhecimento dos sintomas, dificuldade para identificar gravidade e para socorrer, não poder tomar providências, dificuldade na higiene, no entrosamento da criança nas atividades, $e$ falta de recursos materiais e humanos - citados uma vez cada. Uma única trabalhadora não mencionou dificuldades.

Ela vai precisar de mais atenção, ela vai ficar mais quieta, você vai ter que insistir mais para ela comer, coisa assim.

(...) a dificuldade maior, muitas vezes é quando não acha a família para vir buscar (...)

A maioria das entrevistadas disse não saber o que fazer para prevenir, controlar ou diminuir os problemas respiratórios (Gráfico 4), algumas por desconhecerem medidas para isto, e outras por concluírem que não estão ao seu alcance, uma vez que entendem que tais problemas são causados por fatores relacionados à natureza.

Acho que até dá, mas eu não sei o procedimento para terminar com..., eu acho que até tem, na verdade, mas assim especificamente eu não sei.

Como que nós vamos diminuir estes problemas respiratórios, aqui em São Paulo, com esta poluição?

Em relação aos cuidados com o ambiente, aparecem ações relacionadas com a 
limpeza, como deixar o ambiente arejado, sem cortinas e tapetes. Os cuidados diretos à criança são: alimentação, não tomar chuva, friagem, e não andar descalço.

Tem que estar sempre limpinho, não tem que ter muita cortina, muito tapete, tem que estar sempre muito limpinho, tomar bastante líquido, se alimentar bem.

Eu acho que depende muito da própria mãe e do pai, de levarem eles, eles de terem o cuidado de levarem ao médico sempre que necessário (....)

Foram citadas, isoladamente, hipóteses que as trabalhadoras formulam, mas cuja viabilidade desconhecem, como uma vacina, medicamento ou algum trabalho com os pais.

Ah, se tiver algum tipo de trabalho, alguma coisa assim com os pais, alguma coisa assim, dá pra diminuir, mas como, ao certo, eu não sei te dizer.

\section{Discussão}

Os dados de caracterização das trabalhadoras das creches investigadas mostramse um pouco melhores do que os encontrados na rede de creches municipais em São Paulo há poucos anos, quando a maioria possuía apenas ensino fundamental completo ou incompleto (Vico, 2001; Avancini, 2000). Talvez esse fato deva-se à localização das creches em uma região próxima ao centro da cidade, ou porque esteja havendo uma melhoria no quadro, conforme preconizado pela LDB. Ainda assim, uma porcentagem significativa das trabalhadoras tem baixo nível de escolaridade e a maioria não possui capacitação específica para o trabalho com educação infantil, a despeito de atuar na área há muitos anos. Isto mostra como ainda há um grande caminho a ser percorrido até que seja atingido o patamar recomendado na lei quanto à formação profissional dos educadores de creche/pré-escola (Brasil, 1996).

Em relação aos conhecimentos das trabalhadoras sobre IRA, um grande número identifica-os por meio de sinais clínicos, vários destes efetivamente relacionados a essas patologias, mas alguns inespecíficos, pois também se manifestam em outros problemas de saúde. A bronquite foi a principal doença respiratória citada como conhecida, provavelmente por apresentar elevado índice de morbidade. As afecções do trato respiratório superior, como gripe, resfriado, dor de garganta, e otite, apesar da alta incidência na população infantil, foram pouco lembradas. Possivelmente, porque não são compreendidas pelas trabalhadoras como respiratórias, o que denota sua pouca familiaridade com as classificações científicas.

Quase todas as trabalhadoras se referiram à gripe ou ao resfriado como os agravos mais comuns nas creches, o que é compatível com sua incidência, pois se trata de doença "comum" da infância, que ocorre rotineira e repetidamente. Segundo Bricks \& Leone (1996), em estudo realizado em creches da rede pública municipal de São Paulo, os dez principais diagnósticos de morbidade 
Gráfico 4. Medidas citadas pelas trabalhadoras para controlar/diminuir os problemas respiratórios na creche, segundo escolaridade

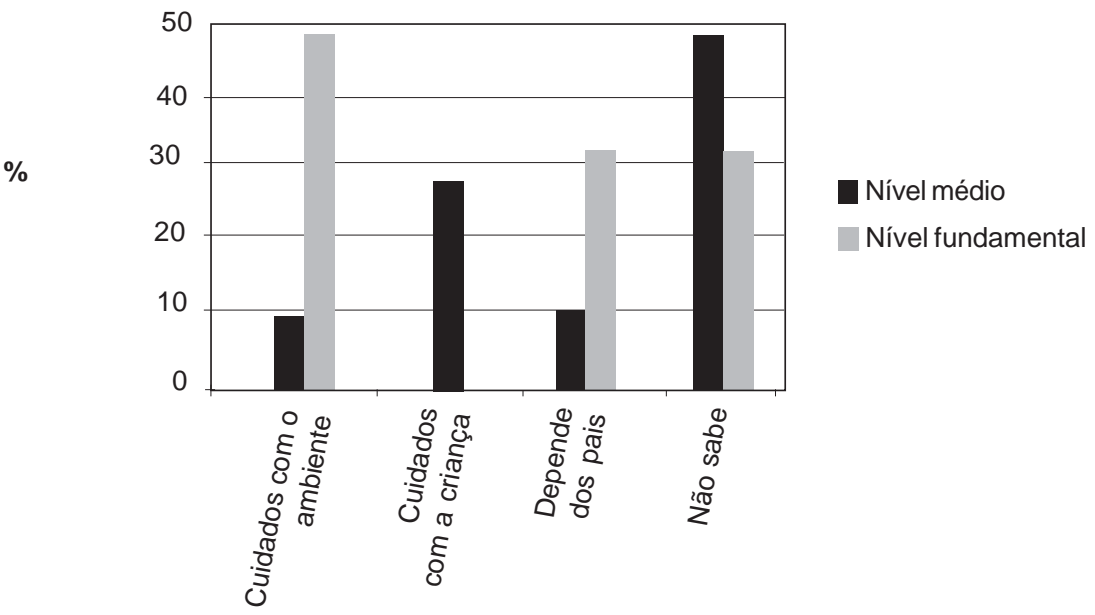

levantados estavam relacionados ao aparelho respiratório, entre eles, resfriado, bronquite e amigdalite.

A pneumonia também foi citada como agravo freqüente nas creches, o que chama a atenção, pois não chega a ser propriamente um agravo freqüente, como as afecções de vias aéreas superiores. Mas a percepção das educadoras se coaduna aos elevados índices de incidência e hospitalização por pneumonia na infância, caracterizando sua maior gravidade, o que pode explicar ser um evento marcante na sua memória. Segundo levantamento feito nas creches em questão, a incidência de pneumonia em crianças menores de três anos, em 2003, foi de 0,16 casos/criança-ano em uma delas, e 0,68 na outra (Veríssimo, 2005). Considerando que estes dados foram obtidos nos registros locais, devem estar subestimados, pois se referem, principalmente, aos casos diagnosticados no período letivo e que deram continuidade ao tratamento na própria creche.

As trabalhadoras mencionaram, como sinais de doença respiratória e de gravidade, tanto sinais específicos como inespecíficos, sendo que os sinais específicos de agravos respiratórios foram citados por um pequeno número de trabalhadoras. Tal como apontado na introdução, é fundamental que os cuidadores de crianças reconheçam os sinais de gravidade que demandam atenção de saúde imediata.

Conforme destacam Chiesa \& Bertolozzi (1997), o desconhecimento dos sinais que realmente demandam intervenção ou indicam gravidade pode resultar em demora na procura de atenção, ou mesmo em não procura $e$, conseqüentemente, em maior probabilidade de agravamento dos casos, restringindo as possibilidades de tratamento e recuperação das crianças $e$ explicando, em parte, os óbitos infantis por esta causa. Também podem levar a 
um excesso de encaminhamentos aos serviços médicos, gerado pela preocupação com todo tipo de sinais.

A grande maioria demonstrou não conhecer as principais causas dos problemas respiratórios, mesclando informações de senso comum e crenças populares a noções oriundas da ciência, incluindo as auxiliares de enfermagem. Assim, relacionam a causa a fatores climáticos e falta de cuidado da mãe. Notamos que a maioria das trabalhadoras não sabe diferenciar os fatores que causam os problemas respiratórios diretamente daqueles que favorecem ou contribuem para o adoecimento.

A preocupação das trabalhadoras com a necessidade da criança transparece quando elas destacam como principal ação chamar a mãe para que ela providencie atenção médica. Por outro lado, são realizadas medidas esporádicas para o controle e prevenção desses agravos na creche. Assim, por exemplo, foram pouco citadas medidas de prevenção de disseminação de infecções, que são imprescindíveis particularmente em ambiente coletivos, tais como a lavagem das mãos, higiene nasal, manter o ambiente ventilado. Apenas uma ADI falou da lavagem das mãos, embora seja considerado princípio universal de higiene. Nas creches, essa prática simples e eficaz é uma das mais difíceis de acontecer, quer seja na freqüencia desejável, quer no modo correto de realizá-la (Maranhão, 1998; Vico, 2001). Isso demonstra que não há sistematização de ações voltadas ao controle de infecções na instituição, o que pode ser devido a dois grupos importantes de razões: conhecimentos limitados sobre causas do adoecimento e a percepção das trabalhadoras quanto às suas funções profissionais.

Observa-se, no discurso das trabalhadoras, apreensão parcial do conhecimento, possivelmente devido ao fato de este se construir no cotidiano, a partir das experiências, mas sem aprofundamento do assunto. Muitas medidas são mencionadas sem compreensão de sua utilidade, como no caso citado da higiene, que é referido como um problema principalmente doméstico, não sendo compreendido como um fator de risco maior na creche do que no domicílio. Tal pode ser observado também nas causas de IRA referidas, como má alimentação e aspectos do ambiente doméstico, que se denota serem relacionadas à precária condição de vida das famílias, enquanto problemas individuais, não havendo uma reflexão mais abrangente das causas sociais e seu impacto sobre a saúde infantil.

Além disto, cerca de metade das trabalhadoras diz não saber o que fazer, ou que na creche não há o que fazer para prevenir e controlar os problemas respiratórios. Isto reforça a falta de conhecimento acerca da importância dos cuidados que realizam com este fim, bem como pode indicar falta de valorização às ações de cuidado, decorrente da compreensão de estas estarem além de suas competências profissionais. Por outro lado, a idéia de que "não há muito que fazer na creche", porque faltam recursos humanos $e$ materiais, sugere que as trabalhadoras pensam em ações de diagnóstico $e$ tratamento específico, as quais, realmente, não são do âmbito de sua competência. Mas, há medidas de proteção à saúde que devem ser implementadas na instituição, de maneira sistemática e fundamentada, garantindo o bem-estar infantil. Embora todas as trabalhadoras apresentemse preocupadas com a situação de saúde das crianças e realizem várias medidas de cuidado, elas percebem-se muito mais limitadas do que são 
realmente, bem como não têm experimentado oportunidades de aprimoramento em questões do cuidado de saúde.

Quanto aos relatos que enfatizam que quem deve cuidar da criança, quando ela adoece, é a mãe, bem como os que culpam a mãe pelo adoecimento infantil $e$ apontam como grande dificuldade encontrar a mãe quando necessário, foi possível perceber uma relação conflituosa entre as trabalhadoras e famílias, que precisa ser melhor identificada e trabalhada. Esta é possivelmente gerada por uma compreensão de que a creche seja uma entidade educativa, e não assistencial, bem como pela concepção materna vigente em nossa sociedade, segundo a qual a mãe é a principal provedora de cuidado e educação infantil.

Entretanto, a creche também tem a função de compartilhar os cuidados e a guarda da criança com a família, o que inclui garantir ambiente saudável e atenção ao desenvolvimento e à saúde individual (Brasil, 1998). A própria decisão de chamar ou não a mãe é de sua competência e depende da capacidade das trabalhadoras para identificar e interpretar os sinais de comprometimento de saúde.

Embora a escolaridade das trabalhadoras não tenha resultado em diferenças em algumas questões, mostrou-se como um fator possivelmente associado aos conhecimentos de causas específicas dos agravos respiratórios, à implementação de ações de controle de transmissão, à utilização de leituras como fonte de conhecimento, e à percepção de pouco conhecimento sobre o tema - respostas apresentadas em maior proporção entre as com nível médio de ensino. Isto aponta a relevância da melhoria do nível educacional das trabalhadoras como intrínseca à possibilidade de oferecer cuidados e educação mais adequados na instituição educativa, mas não suficiente.

Um primeiro desafio é o de que as trabalhadoras assumam o cuidado como ação profissional. Para tanto, além das mudanças na formação, é imprescindível a formação continuada em serviço, que abranja aspectos tanto relativos ao processo educativo como ao cuidado cotidiano. A implementação de cuidados adequados também favorece a formação de hábitos saudáveis nas crianças, que tem início desde a mais tenra idade - o que pode ser alcançado com o componente da educação em saúde com enfoque integral, que abrange inserir educação em saúde no projeto institucional e desenvolver conhecimentos $e$ habilidades para estilos de vida saudáveis.

A estratégia das Escolas Promotoras da Saúde define que a promoção da saúde, no âmbito escolar, tem três componentes relacionados entre si: educação em saúde com enfoque integral, incluindo o desenvolvimento de habilidades para a vida; criação e manutenção de ambientes físicos $e$ psicossociais saudáveis; oferta de serviços de saúde, alimentação saudável e vida ativa (Ippolíto-Shepher, 2003). Os aspectos discutidos neste estudo relacionam-se a estes componentes, razão pela qual afirmamos seu potencial para contribuir para a qualificação do cuidado oferecido na creche.

Particularmente para a realidade das creches e pré-escolas, o documento de credenciamento das creches australianas apresenta propostas aplicáveis que correspondem a esses componentes, como a seguir: toda a equipe é capacitada e pronta a observar sinais de doenças em crianças; a creche oferece apoio $e$ recursos para a equipe e para os pais a respeito de muitos aspectos da saúde e do bem-estar das crianças; a equipe é fiel a princípios de higiene, o que reduz a propagação de doenças infecciosas; a equipe incentiva a criança a seguir regras 
simples de higiene; a equipe está familiarizada com procedimentos médicos, de emergência e em caso de acidentes; a equipe é incentivada a participar de cursos relacionados à saúde infantil e adulta; a equipe se reúne regularmente para discutir saúde infantil e adulta, e para conversar com os pais (Piotto et al., s.d.).

\section{Considerações finais e recomendações}

Pensar a questão do cuidado de saúde na creche e pré-escola não significa substituição da ação da instituição de saúde. Assim, o que se espera das trabalhadoras não é uma ação diagnóstica, mas atuação adequada na prevenção e controle de agravos no cotidiano, ou seja, a sistematização de conhecimentos e práticas que viabilizem o cuidado profissional das crianças, tal como preconizado para as instituições de cuidado e educação infantil.

Dada a magnitude das IRAs na infância, é imprescindível definir metas de qualidade do cuidado nesses ambientes, voltadas para transformar esse quadro. Uma das ações prioritárias seria a educação em saúde na formação e educação continuada das trabalhadoras, proposta na estratégia das Escolas Promotoras de Saúde (Ippolito-Shepher, 2003). Como afirmam Amorim et al. (2000, p.16)

a formação fará com que instituição e educadores passem a

ativamente assumir seu papel de agentes de saúde, tornando-os mais aptos a diagnosticar precocemente e encaminhar mais adequadamente as diferentes doenças que possam acometer as crianças. Além disso, possibilitará que tenham tanto uma perspectiva preventiva, como competência para dar assistência de emergência, em caso de necessidade.

\section{Agradecimentos}

À Fapesp, pelo apoio mediante bolsa de iniciação científica, Processo 02/06967-6.

\section{Referências}

AMORIM, K. S.; YAZLLE, C.; ROSSETTI-FERREIRA, M. C. Binômios saúde-doença e cuidado-educação em ambientes coletivos de educação da criança pequena. Rev. Bras. Cresc. Desenv. Hum., v.10, n.2, p.3-18, 2000.

AVANCINI, M. Pesquisa mostra má qualidade de creches. O Estado de São Paulo. São Paulo, 30 out. 2000. Caderno A, p. 7.

BARRETO, A. M. R. F. Por que e para que uma política de formação do profissional de educação infantil? In: BRASIL. Ministério da Educação e do Desporto. Secretaria de Educação Fundamental. Por uma política de formação do profissional de educação infantil. Brasília: COEDI/MEC, 1994.

BENGUIGUI, Y. Bases técnicas para a prevenção, diagnóstico, tratamento e controle das IRA no primeiro nível de atenção. In: BENGUIGUI, Y.; ANTUÑANO, F. J. L.; SCHMUNIS, G.; YUNES, J. Infecções respiratórias em crianças. Washington: OPAS, 1998. Cap.16, p.335-53 (Série HCT/AIEPI-1.P). 
BRASIL. Lei n 9.394, de 20 de dezembro de 1996. Lei de Diretrizes e bases da Educação Nacional. Estabelece as diretrizes e bases da educação nacional. Diário Oficial da União, Brasília, 23 dez. 1996. p.27833-41.

BRASIL. Ministério da Educação e do Desporto. Secretaria de Educação Fundamental. Referencial curricular nacional para a educação infantil. Brasília, 1998. 3v.

BRASIL. Principais causas de internação em crianças de 0 a 14 anos nos estados de São Paulo, Paraná, Santa Catarina e Rio Grande do Sul. Disponível em: <http:// saudedacrianca.org.br/cis/causas.htm>. Acesso em: 23 maio 2002.

BRICKS, L. F.; LEONE, C. Utilização de medicamentos por crianças atendidas em creches. Rev. Saúde Pública, v.30, n.6, p.527-35, 1996.

CHIESA, A. M.; BERTOLOZZI, M. R. Estudo epidemiológico da mortalidade por infecções do aparelho respiratório em menores de 5 anos da região do Butantã, São Paulo, Brasil. In: BENGUIGUI, Y. Investigações operacionais sobre o controle das infecções respiratórias agudas. Washington: OPAS, 1997. p.19-29. (Série HCT/AIEPI-2)

DATASUS. Indicadores de mortalidade: número de óbitos infantis (menores de 1 ano) por 100 nascidos vivos. Brasil, 1997-2002. Disponível em: <http://tabnet.datasus.gov.br/cgi/idb2004/ c01.htm>. Acesso em 09: ago 2005a.

DATASUS. Indicadores de mortalidade: mortalidade proporcional por grupos de causas (1 a 4 anos) no município de São Paulo, em 2002. Disponível em: <http://tabnet.datasus.gov.br/cgi/ tabcgi.exe?idb2004/c04.def>. Acesso em: 14 dez. 2005b.

DATASUS. Indicadores de mortalidade: mortalidade proporcional por grupos de causas. Período de 1995-1999. Disponível em: <http://tabnet.datasus.gov.br/cgi/deftohtm.exe?idb2004/c04.def>. Acesso em: 19 jan. 2006.

IPPOLÍTO-SHEPHER J. Escuelas promotoras de la salud. Washington: OPAS, 2003; (Série Promoción de la Salud, 4).

MARANHÃO, D. G. O cuidado como elo entre a saúde e a educação: um estudo de caso no berçário de uma creche. 1998. Dissertação (Mestrado) - UNIFESP, São Paulo.

MINAYO, M. C. S. O desafio do conhecimento: pesquisa qualitativa em saúde. 2.ed. São Paulo: Ed. HUCITEC-ABRASCO, 1993. p.197-211.

PIOTTO D. C.; ROSSETI-FERREIRA, M. C.; CHAGURI, A. C.; MELLO A. M.; SILVA, A. P.; ELTINK, C. Promoção da qualidade e avaliação na educação infantil: contribuições da experiência com um instrumento australiano para a discussão brasileira. Ribeirão Preto: s/d. (mimeogr.).

VERÍSSIMO, M. L. Ó R. O olhar de trabalhadoras de creches sobre o cuidado da criança. 2001. Tese (Doutorado) - Escola de Enfermagem, Universidade de São Paulo, São Paulo.

VERÍSSIMO, M. L. Ó R. Ocorrência de agravos respiratórios em creches universitárias e municipais na cidade de São Paulo. Rev. Bras. Cresc. Desenv. Hum., v.15, n.2, p.1-12, 2005.

VERÍSSIMO, M. L. Ó R.; FONSECA, R. M. G. S. O cuidado da criança segundo trabalhadoras de creches. Rev. Latino-am. Enferm., v.11, n.1, p.28-35, 2003.

VERÍSSIMO, M. L. Ó R.; SIGAUD, C. H. S. Assistência de enfermagem à criança com agravos respiratórios. In: (Orgs.). Manual de Enfermagem. Brasília: Ministério da Saúde, 2001. p.95-8.

VICO, E. S. R. Estudo da mortalidade de crianças usuárias de creches no município de São Paulo. 2001. Dissertação (Mestrado) - Faculdade de Saúde Pública, Universidade de São Paulo, São Paulo.

VICTORA, C. G. Fatores de risco nas IRA baixas. In: BENGUIGUI, Y.; ANTUÑANO, F. J. L.; SCHMUNIS, G.; YUNES, J. Infecções respiratórias em crianças. Washington: OPAS, 1998. Cap.3, p.43-61. 
MARTINS, J.; VERÍSSIMO, M. L. Ó. R.

MARTINS, J.; VERÍSSIMO, M. L. Ó. R. Conocimientos y prácticas de trabajadoras de guarderías infantiles municipales relativos al cuidado del niño con infección respiratoria aguda. Interface - Comunic., Saúde, Educ., v.10, n.20, p.487-504, jul/dez 2006.

Este trabajo identificó los conocimientos y prácticas de las trabajadoras de guarderías referentes a la prevención, detección precoz y manejo de las infecciones respiratorias agudas en la infancia, debido a su gran magnitud en esos lugares. Los datos fueron recolectados en entrevistas semiestructuradas, organizados en categorías a través del análisis temático de contenido y los temas fueron cuantificados. Participaron 14 auxiliares de desarrollo infantil y duas auxiliares de enfermería de dos guarderías públicas. La bronquitis fue el agravante más mencionado, y la fiebre, tos y cansancio fueron las señales más referidas de la enfermedad; las señales de gravedad fueron poco citadas; hubo referencia de asociación de las enfermedades con el descuido materno; muchas trabajadoras desconocen las intervenciones para disminuir la ocurrencia de esos agravantes. Parte de esas trabajadoras hizo referencia a acciones apropiadas para el cuidado infantil, la mayoría fundamenta sus acciones en el sentido común y desconoce los cuidados específicos. La mejoría de los conocimientos podrá facilitar la sistematización del cuidado como fue preconizado en el modelo de las Escuelas Promotoras de la Salud.

PALABRAS CLAVE: salud del niño. jardines infantiles. infecciones del tracto respiratorio. práctica profesional. salud escolar.

Recebido em 31/01/05. Aprovado em 31/05/06. 